\title{
Guillain-Barre syndrome induced by pembrolizumab and sunitinib: A case report
}

\author{
CHEN HAN, JIN-AN MA, YING ZHANG, \\ YUNA JIANG, CHUNHONG HU and YUANQIANG WU \\ Department of Oncology, The Second Xiangya Hospital of Central South University, \\ Changsha, Hunan 410011, P.R. China
}

Received September 25, 2019; Accepted March 5, 2020

DOI: $10.3892 / \mathrm{mco} .2020 .2042$

\begin{abstract}
Pembrolizumab, an immune checkpoint inhibitor against the programmed death-1 pathway, has been used in combination with acitinib for the first-line treatment of advanced renal cell carcinoma. Neurotoxicity is a rare immune-related adverse event (irAE). The present study reports a case of Guillain-Barre syndrome (GBS) induced by pembrolizumab and sunitinib, and reviews other previous studies to elucidate the clinical characteristics and suitable management of this rare irAE. An advanced renal cell carcinoma patient who received several cycles of pembrolizumab combined with sunitinib developed limb weakness and numbness of the extremities, and was diagnosed with GBS by electrodiagnostic and cerebrospinal fluid examination. The patient improved after treatment with intravenous immunoglobulin along with prednisone. To the best of our knowledge, this is the first case of GBS during treatment with pembrolizumab in combination with sunitinib in advanced renal cell carcinoma.
\end{abstract}

\section{Introduction}

Programmed death-1 (PD-1) inhibitors, including pembrolizumab and nivolumab, can activate T cells to kill tumor cells by blocking the binding of the PD-1 receptor and programmed death ligand 1 and 2 (PD-L1 and PD-L2) (1). It is important to note that the dramatic efficacies of PD-1 inhibitors commonly accompanied by fatal side effects such as cardiotoxicity, pneumonitis and neurological toxicities (2). Guillain-Barre syndrome (GBS) is a rare but fatal autoimmune-mediated peripheral neuropathy characterized by muscular weakness in the extremities and peripheral paresthesia. The pathogenesis

Correspondence to: Professor Jin-An Ma, Department of Oncology, The Second Xiangya Hospital of Central South University, 139 Renmin Road, Changsha, Hunan 410011, P.R. China E-mail:majinancs@csu.edu.cn

Key words: Guillain-Barre syndrome, pembrolizumab, immunecheckpoint inhibitor, sunitinib, renal cell carcinoma, intravenous immunoglobulin of GBS is the autoimmune response caused by molecular mimicry between microbial and nerve antigens (3). The present study reports on the case of a patient with advanced renal cell carcinoma who received pembrolizumab combined with sunitinib and presented with GBS. To date, no similar case has been reported. We reviewed some literatures to analyze the underlying mechanism of this rare disease and we aim to highlight that early recognition and suitable management is crucial to improve patient outcomes.

\section{Case report}

A 55-year-old male presented with a right renal mass on CT scan. He was diagnosed with renal clear cell carcinoma with sarcomatoid differentiation after robot-assisted laparoscopic resection of the local mass (Fig. 1). Adjuvant targeted therapy with sunitinib (50 mg/day; 2 weeks on, 1 week off) was performed for six cycles. On March 21st 2018, a CT scan revealed local recurrence, and spleen and abdominal cavity metastasis (Fig. 2). As a result of this, the patient was started on pembrolizumab $(2 \mathrm{mg} / \mathrm{kg}$ once every 3 weeks) combined with sunitinib $(37.5 \mathrm{mg} / \mathrm{day} ; 2$ weeks on, 1 week off) on March 27th 2018. After 4 months, the patient developed limb weakness and numbness of the extremities. Neurological examination showed paresthesia of the four extremities, absence of tendon reflex of the limbs, and a mild decrease in muscle strength of the limbs with a grade of $4 / 5$, but no pathological reflex was observed. This patient had no history of GBS, and laboratory examination results showed no evidence of infection. Procalcitonin, c-reactive protein, influenza virus antibody, cytomegalovirus antibody, rubella virus antibody, herpes simplex virus antibody, Epstein-Barr virus antibody, detection of mycoplasma and chlamydia DNA, and hepatitis virus tests were all negative. Rheumatic immune disease was also ruled out. Magnetic resonance imaging of the brain and spinal cord was normal. Cerebrospinal fluid (CSF) analysis showed albuminocytologic dissociation (protein, $583.30 \mathrm{mg} / \mathrm{l}$; cell count, 8,000/ $/ \mathrm{l}$ ), and Pandy's test was positive. Electroneuromyography revealed acute motor and sensory axonal neuropathy (Fig. 3). Based on these results, the patient was diagnosed with GBS, which can be induced by pembrolizumab. Pembrolizumab was permanently 

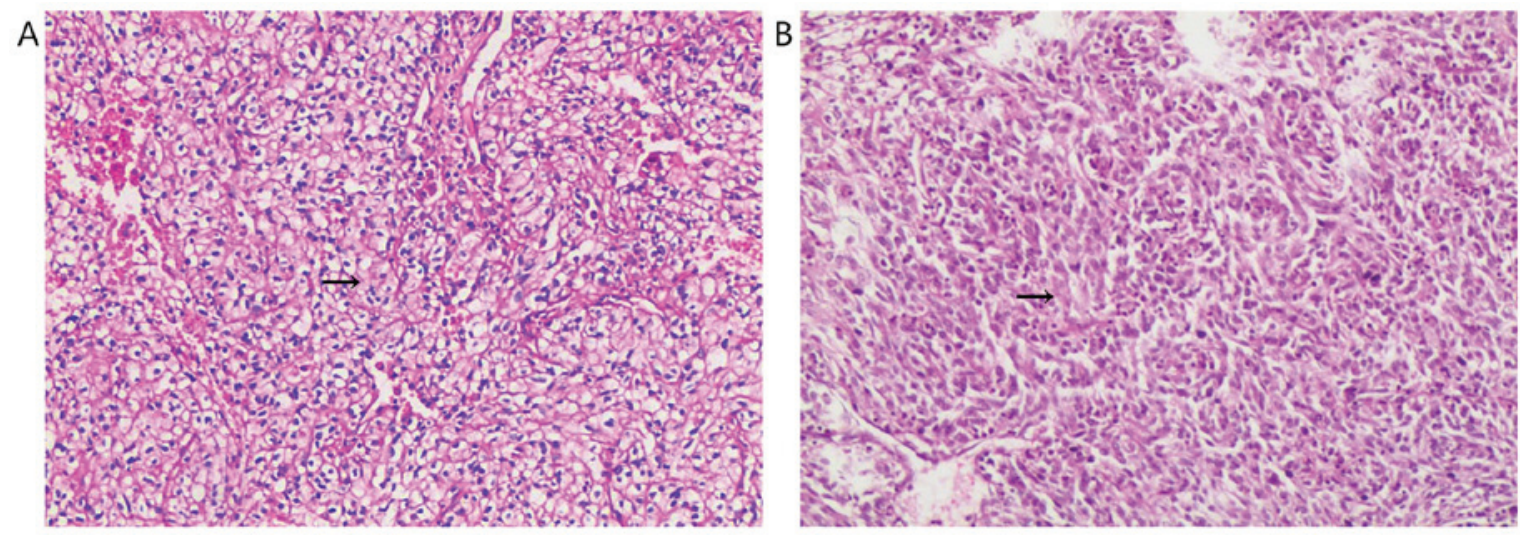

Figure 1. Pathological findings. (A) Pathological analysis of the resected tumor specimen revealing clear cellular renal cell carcinoma (Fuhrman nuclear grade 2) with (B) sarcomatoid differentiation (stain, hematoxylin and eosin). Magnification, x100. Arrows indicate clear cellular renal cell carcinoma (Fuhrman nuclear grade 2) and sarcomatoid differentiation.
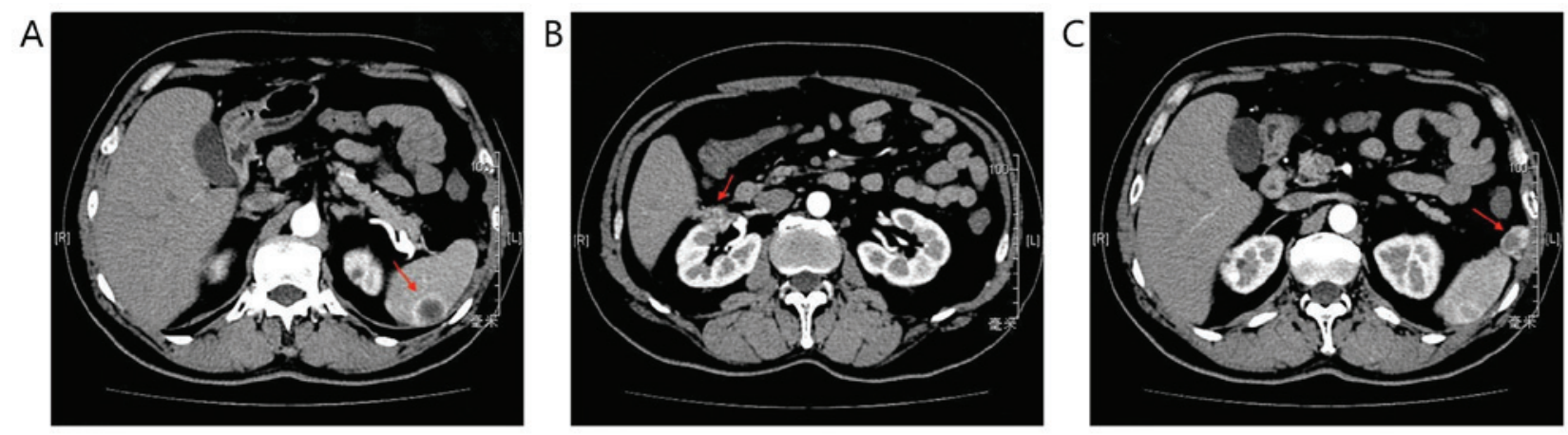

Figure 2. CT scanning before combination therapy in March 2018. (A) Spleen metastasis: The arrow indicates the spleen mass. (B) Local recurrence: The arrow indicates right renal mass. (C) Abdominal cavity metastasis: The arrow indicates abdominal cavity mass.

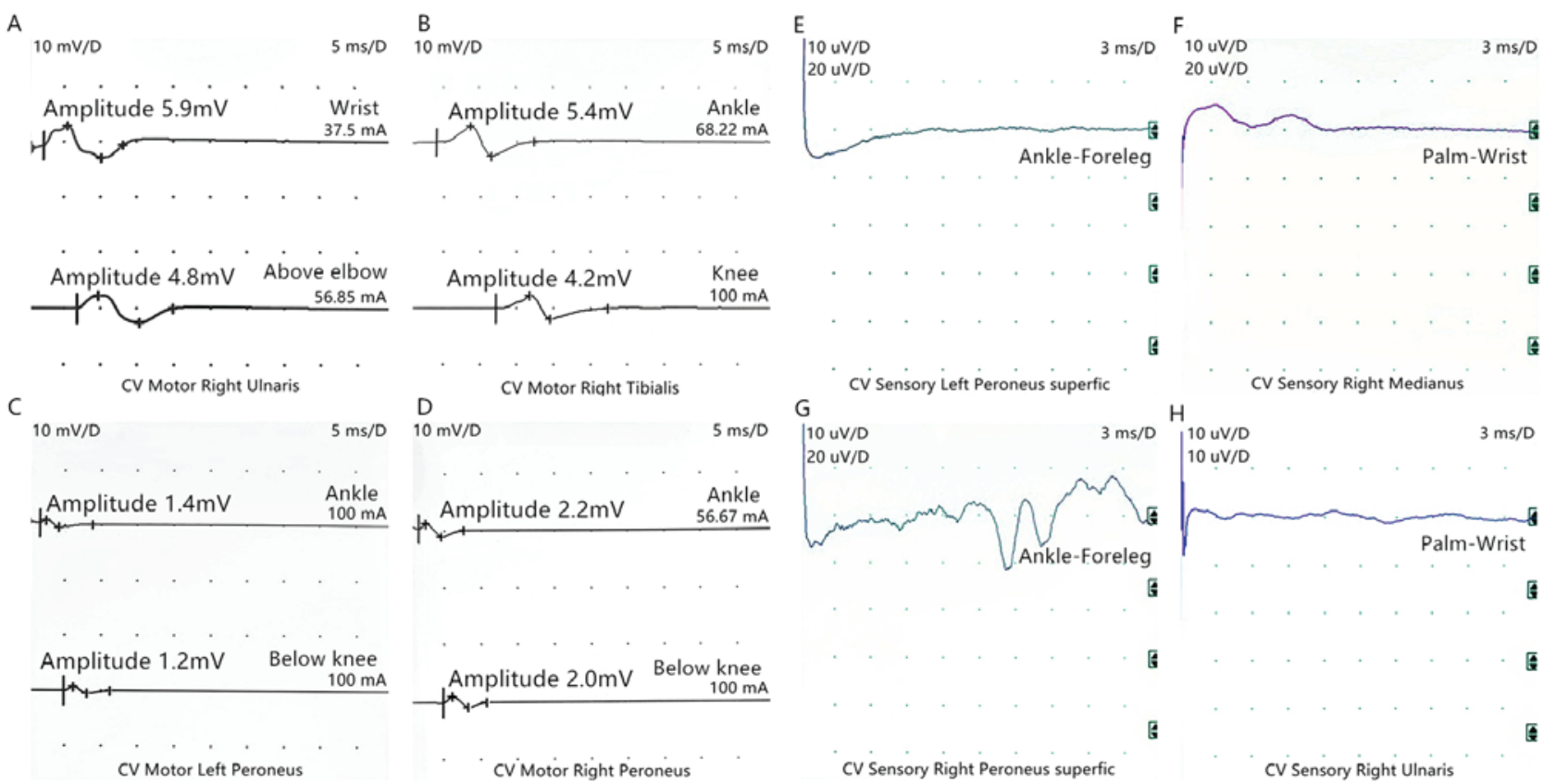

Figure 3. Electrophysiological examinations of motor nerves (scanning speed: $5 \mathrm{~ms} / \mathrm{D}$, sensitivity: $10 \mathrm{mV} / \mathrm{D}$ ). (A) Amplitude of motor waves of right ulnar nerve decreased (wrist: $5.9 \mathrm{mV}$, above elbow: $4.8 \mathrm{mV}$ ). (B) Amplitude of motor waves of right tibial nerve decreased (ankle: $5.4 \mathrm{mV}$, knee: $4.2 \mathrm{mV}$ ). (C) Amplitude of motor waves of left peroneal nerve decreased (Ankle: $1.4 \mathrm{mV}$, Below knee: $1.2 \mathrm{mV}$ ). (D) Amplitude of motor waves of Right peroneal nerve is normal (Ankle: $2.2 \mathrm{mV}$, Below knee: $2.0 \mathrm{mV}$ ). Normal range of the amplitude of motor nerves are as follow: Ulnar nerve: $\geq 5.0 \mathrm{mV}$, tibial nerve: $\geq 4.8 \mathrm{mV}$ and peroneal nerve: $\geq 2.0 \mathrm{mV}$. Electrophysiological examinations of sensory waves (Scanning speed: $3 \mathrm{~ms} / \mathrm{D}$, Sensitivity: $10 \mathrm{uV} / \mathrm{D}$ ): The Sensory waves of (E) left superficial peroneal nerve, $(\mathrm{F})$ right median nerve, $(\mathrm{G})$ right superficial peroneal nerve and $(\mathrm{H})$ right ulnar nerve $(\mathrm{H})$ were not induced. Normal range of distal sensory nerve action potential: Median nerve: $\geq 13.86 \mu \mathrm{V}$; ulnar nerve: $\geq 10.77 \mu \mathrm{V}$; and sural nerve: $\geq 7.71 \mu \mathrm{V}$. 
discontinued due to this severe immune-related adverse event (irAE). The symptoms were gradually aggravated after oral treatment with dexamethasone $(10 \mathrm{mg} /$ day $)$. The patient was then switched to intravenous immunoglobulin (IVIG; $0.4 \mathrm{~g} / \mathrm{kg}$ for 5 days) along with prednisone $(1 \mathrm{mg} / \mathrm{kg}$ per day). The patient's symptoms improved during 1 week of treatment. After 1 month, although he experienced difficulty with fine movements, he was able to walk and stand normally, and the doctors began to taper off the prednisone dosage. CT scan reexamination showed that the masses in the right kidney and abdominal cavity had disappeared, and the enhancement degree of spleen metastases was reduced (Fig. 4). No recurrence was observed during the 10 months of follow-up.

\section{Discussion}

Pembrolizumab is a potent and highly selective fully human IgG4 PD-1 immune-checkpoint inhibitor. Studies have confirmed its efficacy in several types of advanced cancer, such as melanoma, non-small cell lung cancer, head and neck carcinoma and renal cancer (3-6). Immunotherapy can cause a series of irAEs, including skin reactions, colitis, hepatitis, endocrinopathies, pneumonitis and, rarely, neurological toxicity $(7,8)$.

GBS is an autoimmune-mediated disease in which most patients have prodromal infection. Common infectious pathogens include cytomegalovirus, Epstein-Barr virus, influenza virus, human immunodeficiency virus, mycoplasma, Haemophilus and Campylobacter jejuni (1). It is now believed that the primary pathogenesis is the autoimmune response caused by molecular mimicry between microbial and nerve antigens. Both cellular and humoral immunity are abnormally activated. $T$ cells invade the peripheral nerves, and peripheral demyelination is mediated by macrophages. Immunoglobulin and complement deposits appear on the myelin sheath and Schwann cells (9). Regulatory T cells (Treg cells) can downregulate the immune response, maintain autoimmunological tolerance, and prevent autoimmune diseases (10). The binding of PD-1 and its ligands PD-L1/PD-L2 causes CD25 $5^{+}$Foxp $^{+}$Treg cells to suppress anti-tumor immunity (11), and an increase in the number of $\mathrm{CD} 25^{+} \mathrm{Foxp}^{+}$Treg cells has been reported in many malignant tumors (12-15), which is often associated with poor prognosis (16). The effect of PD-1 inhibitors is not limited to tumor-specific T cells, and blocking PD-1/PD-L1 and PD-L2 signals not only promotes anti-tumor immunity, but it also inhibits the generation of Treg cells in normal tissues, causing autoimmune adverse events (11). The patient in the present study had no symptoms of preexisting infection, and influenza virus, Epstein-Barr virus, human immunodeficiency virus, mycoplasma, hepatitis virus and cytomegalovirus infection were excluded by laboratory tests. It has been suggested that pembrolizumab may cause immune hyperfunction by increasing $\mathrm{T}$ cell activity, promoting $\mathrm{T}$ cell proliferation and inhibiting Treg cell function, thus disrupting immune homeostasis and inducing GBS.

Sunitinib is a multi-target tyrosine kinase receptor inhibitor targeting vascular endothelial growth factor receptor (VEGFR)-1, VEGFR-2, VEGFR-3, platelet-derived

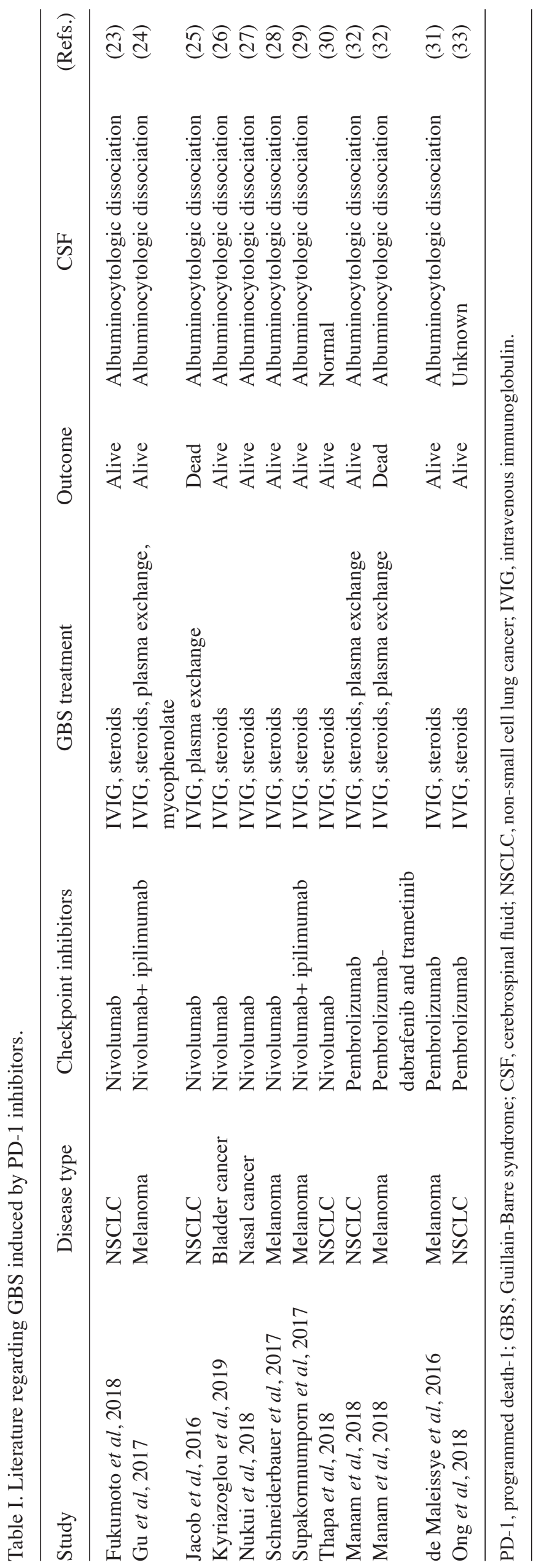



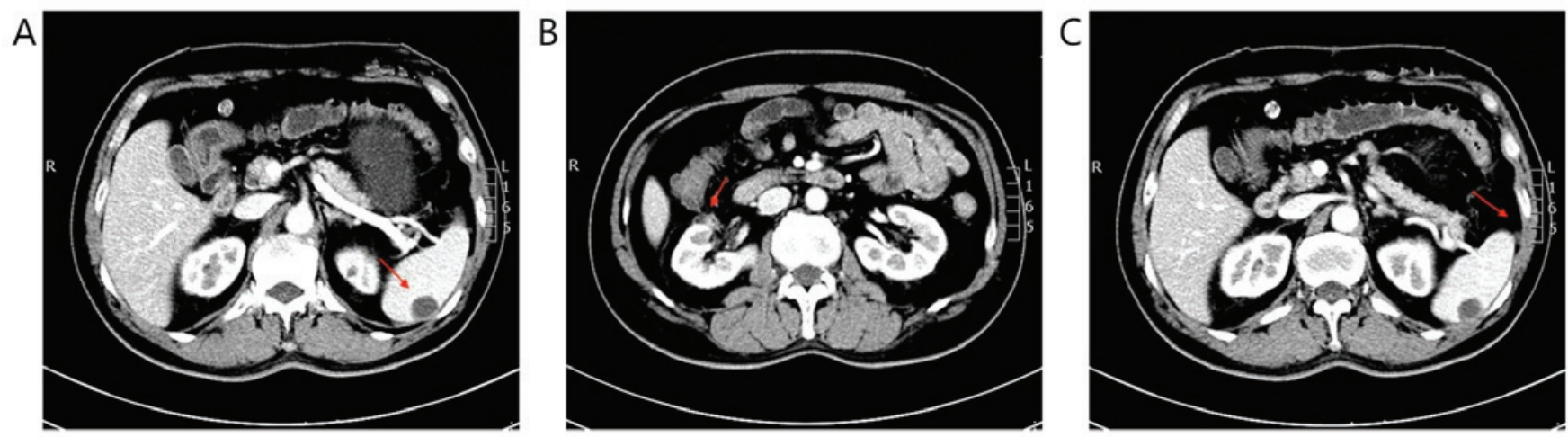

Figure 4. CT scanning after combination therapy in August 2018. (A) Arrow indicates the enhancement degree of spleen metastases was reduced. (B) Arrow indicates the right renal mass has disappeared. (C) Arrow indicates the abdominal cavity metastasis has disappeared.

growth factor- $\alpha$ receptor (PDGFR- $\alpha$ ), PDGFR- $\beta$, stem cell receptor and colony-stimulating factor 1 receptor, which was approved by the US Food and Drug Administration for the first-line treatment of metastatic renal cell carcinoma, and postoperative adjuvant treatment of renal cell carcinoma with a high risk of recurrence $(17,18)$. In the KEYNOTE-426 study, pembrolizumab in combination with acitinib for advanced renal cell carcinoma significantly improved median progression-free survival (15.1 months vs. 11.1 months) over sunitinib alone (6), suggesting that pembrolizumab combined with a multi-target tyrosine kinase receptor inhibitor may be a promising treatment option. The most common side effects of sunitinib include fatigue, anorexia, hypertension, myelosuppression, diarrhea, mucositis, rashes and hand-foot syndrome (19). GBS developed in the patient in the present study, who had favorable responses to sunitinib in combination with pembrolizumab. Currently, two cases of GBS induced by sunitinib have been reported $(20,21)$, to the best of our knowledge, and the mechanism may be related to the sunitinib-mediated inhibition of VEGFRs causing a corresponding increase in VEGF levels, which increases the numbers of B lymphocytes and immature myeloid cells (22). Elevated VEGF levels may also disrupt the blood-nerve barrier by altering microvascular permeability (22). Considering that both $\mathrm{T}$ cells and $\mathrm{B}$ cells are important in the pathogenesis of GBS, it is speculated that combination therapy may have a synergistic pathogenicity. However, further studies are warranted to confirm this hypothesis.

Management of irAEs must never be disregarded. In the PubMed database, eight cases of nivolumab and four cases of pembrolizumab causing GBS have been reported (23-33) (Table I). Many of these cases were treated with nivolumab or pembrolizumab monotherapy (10/13); two patients were treated with ipilimumab and nivolumab in combination, and one was treated with pembrolizumab followed by sequential dabrafenib and trametinib. Most cases were male (9/12), and the neurological symptoms were mostly sensory and movement disorders, and reduced or absent deep tendon reflexes and only one patient had a precursor infection. CSF tests showed that a high proportion of patients had albuminocytologic dissociation (9/12), and the etiological examinations were all negative. Most patients recovered with corticoste- roids, IVIG and plasmapheresis, but two died of respiratory failure. The present patient did not improve with corticosteroids alone, but IVIG was effective, suggesting that IVIG may be suitable for checkpoint inhibitor-induced peripheral neuropathy, although corticosteroids are recommended for the management of irAEs. To the best of our knowledge, this is the first case of GBS during treatment with pembrolizumab in combination with sunitinib in advanced renal cell carcinoma, highlighting the importance of correctly identifying immune-related neurotoxicity and accumulating experience in the management of GBS induced by pembrolizumab and sunitinib.

\section{Acknowledgements}

Not applicable.

\section{Funding}

No funding was received.

\section{Availability of data and materials}

All data generated or analyzed during the present study are included in this published article.

\section{Authors' contributions}

CHa designed the experiments and wrote the initial draft of the manuscript. JM, YZ, YJ, CHu and YW performed the experiments and assisted in the preparation of the manuscript. JM and YZ analyzed the data. $\mathrm{CHa}, \mathrm{CHu}$ and $\mathrm{YW}$ revised the manuscript. All authors read and approved the final manuscript.

\section{Ethics approval and consent to participate}

Not applicable.

\section{Patient consent for publication}

The reported case has been approved by the patient for academic exchange only. 


\section{Competing interests}

The authors declare that they have no competing interests.

\section{References}

1. Wijdicks EF and Klein CJ: Guillain-barré syndrome. Mayo Clin Proc 92: 467-479, 2017.

2. Barbee MS, Ogunniyi A, Horvat TZ and Dang TO: Current status and future directions of the immune checkpoint inhibitors ipilimumab, pembrolizumab, and nivolumab in oncology. Ann Pharmacother 49: 907-937, 2015.

3. Robert C, Schachter J, Long GV, Arance A, Grob JJ, Mortier L, Daud A, Carlino MS, McNeil C, Lotem M, et al: Pembrolizumab versus Ipilimumab in Advanced Melanoma. N Engl J Med 372: 2521-2532, 2015

4. Herbst RS, Baas P, Kim DW, Felip E, Pérez-Gracia JL, Han JY, Molina J, Kim JH, Arvis CD, Ahn MJ, et al: Pembrolizumab versus docetaxel for previously treated,PD-L1-positive, advanced non-small-cell lung cancer (KEYNOTE-010): A randomised controlled trial. Lancet 387: 1540-1550, 2016.

5. Seiwert TY, Burtness B, Mehra R, Weiss J, Berger R, Eder JP, Heath K, McClanahan T, Lunceford J, Gause C, et al: Safety and clinical activity of pembrolizumab for treatment of recurrent or metastatic squamous cell carcinoma of the head and neck (KEYNOTE-012): An open-label, multicentre, phase 1B trial. Lancet Oncol 17: 956-965, 2016.

6. Rini BI, Plimack ER, Stus V, Gafanov R, Hawkins R, Nosov D, Pouliot F, Alekseev B, Soulières D, Melichar B, et al: Pembrolizumab plus axitinib versus sunitinib for advanced renal-cell carcinoma. N Engl J Med 380: 1116-1127, 2019.

7. Haanen JBAG, Carbonnel F, Robert C, Kerr KM, Peters S, Larkin J and Jordan K; ESMO Guidelines Committee: Management of toxicities from immunotherapy: ESMO clinical practice guidelines for diagnosis, treatment and follow-up. Ann Oncol 28 (suppl 4): iv119-iv142, 2017.

8. Brahmer JR, Lacchetti C, Schneider BJ, Atkins MB, Brassil KJ, Caterino JM, Chau I, Ernstoff MS, Gardner JM, Ginex P, et al: Management of immune-related adverse events in patients treated with immune checkpoint inhibitor therapy: American society of clinical oncology clinical practice guideline. J Clin Oncol 36: 1714-1768, 2018.

9. van den Berg B, Walgaard C, Drenthen J, Fokke C, Jacobs BC and van Doorn PA: Guillain-Barre syndrome: Pathogenesis, diagnosis, treatment and prognosis. Nat Rev Neurol 10: 469-482, 2014.

10. Smigiel KS, Srivastava S, Stolley JM and Campbell DJ: Regulatory T-cell homeostasis: Steady-state maintenance and modulation during inflammation. Immunol Rev 259: 40-59, 2014

11. Kumar P, Bhattacharya P and Prabhakar BS: A comprehensive review on the role of co-signaling receptors and Treg homeostasis in autoimmunity and tumor immunity. J Autoimmun 95: 77-99, 2018.

12. Fujii H, Josse J, Tanioka M, Miyachi Y, Husson F and Ono M: Regulatory $\mathrm{T}$ cells in melanoma revisited by a computational clustering of FOXP3+ T cell subpopulations. J Immunol 196: 2885-2892, 2016.

13. Ormandy LA, Hillemann T, Wedemeyer H, Manns MP, Greten TF and Korangy F: Increased populations of regulatory $\mathrm{T}$ cells in peripheral blood of patients with hepatocellular carcinoma. Cancer Res 65: 2457-2464, 2005.

14. Tao H, Mimura Y, Aoe K, Kobayashi S, Yamamoto H, Matsuda E, Okabe K, Matsumoto T, Sugi K and Ueoka H: Prognostic potential of FOXP3 expression in non-small cell lung cancer cells combined with tumor-infiltrating regulatory $\mathrm{T}$ cells. Lung Cancer 75: 95-101, 2012.

15. Syed Khaja AS, Toor SM, El Salhat H, Faour I, Ul Haq N, Ali BR and Elkord E: Preferential accumulation of regulatory T cells with highly immunosuppressive characteristics in breast tumor microenvironment. Oncotarget 8: 33159-33171, 2017.
16. Takeuchi $\mathrm{Y}$ and Nishikawa $\mathrm{H}$ : Roles of regulatory $\mathrm{T}$ cells in cancer immunity. Int Immunol 28: 401-409, 2016.

17. Motzer RJ, Hutson TE, Tomczak P, Michaelson MD, Bukowski RM, Rixe O, Oudard S, Negrier S, Szczylik C, Kim ST, et al: Sunitinib versus interferon alfa in metastatic renal-cell carcinoma. N Engl J 356: 115-124, 2007.

18. Ravaud A, Motzer RJ, Pandha HS, George DJ, Pantuck AJ, Patel A, Chang YH, Escudier B, Donskov F, Magheli A, et al: Adjuvant sunitinib in high-risk renal-cell carcinoma after nephrectomy. N Engl J Med 375: 2246-2254, 2016.

19. Randrup Hansen C, Grimm D, Bauer J, Wehland M and Magnusson NE: Effects and side effects of using sorafenib and sunitinib in the treatment of metastatic renal cell carcinoma. Int J Mol Sci 18: pii: E461, 2017.

20. Mulherin B, Loconte NK and Holen KD: Guillain-Barre syndrome after treatment with sunitinib malate? Oncology (Williston Park) 22: 66-67, 2008.

21. Kanaan Z, Kulairi Z, Titianu M, Saha S and Kumar S: Guillain-barre syndrome following treatment with sunitinib malate. Case Rep Oncol Med 2014: 712040, 2014.

22. Aparicio-Gallego G, Blanco M, Figueroa A, Garcia-Campelo R, Valladares-Ayerbes M, Grande-Pulido E and Anton-Aparicio L: New insights into molecular mechanisms of sunitinib-associated side effects. Mol Cancer Ther 10: 2215-2223, 2011.

23. Fukumoto Y, Kuwahara M, Kawai S, Nakahama K and Kusunoki S: Acute demyelinating polyneuropathy induced by nivolumab. J Neurol Neurosurg Psychiatry 89: 435-437, 2018

24. Gu Y, Menzies AM, Long GV, Fernando SL and Herkes G: Immune mediated neuropathy following checkpoint immunotherapy. J Clin Neurosci 45: 14-17, 2017.

25. Jacob A, Unnikrishnan DC, Mathew A, Thyagarajan B and Patel S: A case of fatal Guillain-Barre syndrome from anti-PD1 monoclonal antibody use. J Cancer Res Clin 142: 1869-1870, 2016.

26. Kyriazoglou A, Liontos M, Papadopoulos C, Bilali A, Kostouros E, Pagoni S, Doumas K, Dimopoulos MA and Bamias A: Guillain-barre syndrome related to nivolumab: Case report of a patient with urothelial cancer and review of the literature. Clin Genitourin Cancer 17: e360-e364, 2019.

27. Nukui T, Nakayama Y, Yamamoto M, Taguchi Y, Dougu N, Konishi H, Hayashi T and Nakatsuji Y: Nivolumab-induced acute demyelinating polyradiculoneuropathy mimicking Guillain-Barre syndrome. J Neurol Sci 390: 115-116, 2018.

28. Schneiderbauer R, Schneiderbauer M, Wick W, Enk AH, Haenssle HA and Hassel JC: PD-1 antibody-induced guillain-barre syndrome in a patient with metastatic melanoma. Acta Derm Venereol 97: 395-396, 2017.

29. Supakornnumporn S and Katirji B: Guillain-barre syndrome triggered by immune checkpoint inhibitors: A case report and literature review. J Clin Neuromuscul 19: 80-83, 2017.

30. Thapa B, Khalid S, Vakili R, Ui J and Misbah S: Nivolumab-associated Guillain-barre syndrome in a patient with non-small-cell lung cancer. Am J Ther 25: e761-e763, 2018.

31. de Maleissye MF, Nicolas G and Saiag P: Pembrolizumab-induced demyelinating polyradiculoneuropathy. N Engl J Med 375: 296-297, 2016.

32. Manam R, Martin JL, Gross JA, Chaudhary D, Chowdhary S, Espinosa PS and Santos ES: Case reports of pembrolizumab-induced acute inflammatory demyelinating polyneuropathy. Cureus 10: e3371, 2018.

33. Ong S, Chapman J, Young G and Mansy T: Guillain-Barre-like syndrome during pembrolizumab treatment. Muscle Nerve 58: e8-e10, 2018.

This work is licensed under a Creative Commons Attribution-NonCommercial-NoDerivatives 4.0 International (CC BY-NC-ND 4.0) License. 